\title{
ISQUEMIA HEPÁTICA NORMOTÉRMICA EM RATOS: ESTUDO DA LESÃO CELULAR ATRAVÉS DO USO DE CLAMPEAMENTO PEDICULAR CONTÍNUO E INTERMITENTE
}

\author{
NORMOTHERMIC HEPATIC ISCHEMIA IN RATS: STUDY OF CELULAR INJURY \\ BY THE USE OF CONTINUOUS AND INTERMITTENT PEDICULAR CLAMPING
}

Fabio Neves da Silva, TCBC-RJ ${ }^{1}$

\begin{abstract}
RESUMO: Objetivo: Avaliar as alterações bioquímicas decorrentes da isquemia hepática normotérmica, seguida de reperfusão em duas modalidades de clampeamento da tríade portal em ratos. Método: Trinta ratos Wistar machos pesando entre 250 e 320 gramas foram divididos em três grupos de 10 animais cada. Induzimos 40 minutos de isquemia hepática por clampeamento pedicular contínuo (grupo I) ou intermitente (grupo II). No grupo controle não houve clampeamento. Como parâmetro de lesão hepatocelular adotamos a concentração plasmática de: transaminase glutâmico oxalacética (TGO), transaminase glutâmico pirúvica (TGP) e lactato desidrogenase (LDH). Colhemos as amostras de sangue no início (T1) e no final da cirurgia (T2). Todos os animais foram submetidos ao mesmo tempo operatório: 60 minutos.Resultados: Não houve diferença estatística nos valores iniciais (T1) das três enzimas nos três grupos. Todos apresentaram aumento significativo das enzimas do momento 1 (T1) para o momento 2 (T2). Houve diferença estatística no aumento médio de TGO e TGP entre os três grupos, sendo o maior aumento encontrado no grupo I e o menor, no grupo controle. Não houve diferença significativa, em relação à LDH, entre o grupo II e o grupo controle. No grupo I, entretanto, houve aumento significativo em relação aos demais. Conclusão: Comparado ao clampeamento contínuo, para um período total de 40 minutos de isquemia, o clampeamento da tríade portal em ratos realizado de forma intermitente, com ciclos de 10 minutos de isquemia e 5 minutos de reperfusão, provoca menor dano hepatocelular, o que foi constatado pela menor alteração enzimática.
\end{abstract}

Descritores: Fígado - irrigação sangüínea; Isquemia; Reperfusão; Constrição; Ratos.

\section{INTRODUÇÃO}

Por receber todo o retorno da circulação esplâncnica através da veia porta, além do suprimento arterial pela artéria hepática, o fígado é o órgão abdominal com maior fluxo de sangue (cerca de $1.500 \mathrm{ml} / \mathrm{min})^{1}$. Exerce grande variedade de funções incluindo o metabolismo de carboidratos, lipídios, proteínas e fatores de coagulação; metabolismo e armazenamento de vitaminas; produção de bile, detoxificação e excreção de endo e exotoxinas.

O controle do sangramento durante a cirurgia hepática é fator prognóstico essencial quanto à mortalidade e morbidade pós-operatória. Diversos métodos baseados na interrupção do aporte sangüíneo ao fígado vêm sendo amplamente estudados e desenvolvidos. Cada um destes métodos possui indicações precisas. Todos apresentam, no entanto, em maior ou menor grau os inconvenientes da hipóxia tecidual, refletidos em graus variados de alterações histológicas e funcionais induzidos pela isquemia.

Os métodos de controle seletivo são indicados preferencialmente, por permitirem a irrigação de grande parte ou de todo o tecido não ressecado. São técnicas amplamente utilizadas, especialmente nas ressecções anatômicas ou em pacientes com pouca reserva funcional. A maio-

1. Mestre em Cirurgia Geral (Setor Abdominal) pela Universidade Federal do Rio de Janeiro - UFRJ. Doutorando em Cirurgia Geral (Setor Abdominal) pela Universidade Federal do Rio de Janeiro — UFRJ. Cirurgião Geral do Hospital Geral de Ipanema, RJ. Cirurgião Geral do Hospital Central da Polícia Militar, RJ.

Recebido em 22/11/2001

Aceito para publicação em 13/08/2002

Trabalho desenvolvido no Setor de Cirurgia Experimental da Universidade Federal do Rio de Janeiro - UFRJ. 
ria dos pacientes, entretanto, não se enquadra neste grupo. Pertencem àquele cujas lesões de localização central, bilateral ou próxima a estruturas vasculares nobres impõem um controle mais amplo e efetivo do sangramento. Além disso, nas cirurgias realizadas em caráter de emergência, por trauma aberto ou fechado, é fundamental que o controle do sangramento seja obtido através do método mais rápido, eficaz e de mais fácil execução. Nestes casos o clampeamento de todo o pedículo hepático é o mais indicado.

$\mathrm{Na}$ impossibilidade da seletividade da isquemia devemos ponderar sobre as vantagens de minimizar a perda sangüínea, com as conseqüências da isquemia no fígado remanescente, especialmente nos casos de hepatectomias extensas e clampeamentos prolongados. Com este objetivo foi desenvolvida a técnica de clampeamento pedicular intermitente, permitindo a restauração temporária do fluxo hepático em ciclos regulares ${ }^{2,3}$. O objetivo deste trabalho foi avaliar, através de um estudo experimental, se o clampeamento intermitente do pedículo hepático provoca menor lesão celular quando comparado ao clampeamento contínuo, o que poderia minimizar as consequiências da isquemia hepática normotérmica.

\section{MÉTODO}

Foram utilizados nesta pesquisa 30 ratos Wistar, machos, pesando entre 250 e 320 gramas provenientes do biotério do Setor de Cirurgia Experimental do Departamento de Cirurgia da Faculdade de Medicina da Universidade Federal do Rio de Janeiro.

Todos os animais foram mantidos em condições idênticas de alimentação e água, oferecidos, sem restrição, no período pré-operatório. Foram submetidos a jejum para sólidos desde a noite que antecedeu a cirurgia e operados pela manhã, sendo aleatória a escolha do animal na composição dos grupos.

Os procedimentos cirúrgicos foram realizados sob anestesia inalatória com éter, inicialmente em campânula fechada e posteriormente com algodão embebido no mesmo anestésico e introduzido em cilindro de vidro ou plástico onde a cabeça do animal era parcialmente introduzida. Após a fixação do animal na mesa cirúrgica, era realizada tricotomia abdominal ampla, anti-sepsia com álcool iodado e iniciada a cirurgia.

$\mathrm{O}$ acesso à cavidade abdominal foi obtido por meio de incisão mediana, partindo do apêndice xifóide e estendendo-se $5 \mathrm{~cm}$ no sentido caudal.

Foram colhidas amostras de sangue por punção da veia cava inferior supra-hepática no início (T1) e no final de 60 minutos de cirurgia (T2). As amostras eram acondicionadas, centrifugadas e analisadas no mesmo dia para dosagem de transaminase glutâmico oxalacética (TGO), transaminase glutâmico pirúvica (TGP) e lactato desidrogenase (LDH).

Os 30 ratos Wistar foram divididos em três grupos de 10 animais cada, de acordo com o tipo de operação executada (Figura 1):

- Grupo I (Clampeamento contínuo da tríade portal): após 15 minutos de laparotomia, identificava-se a tríade portal, que era comprimida pela aplicação de clampes vasculares (Figura 2). O fluxo hepático era interrompido por 40 minutos, quando se retirava o clampe. $\mathrm{O}$ fígado era reperfundido por 5 minutos, momento em que se colhia nova amostra de sangue. Procedia-se, então, à síntese da aponeurose e pele com algodão 000 em sutura contínua.

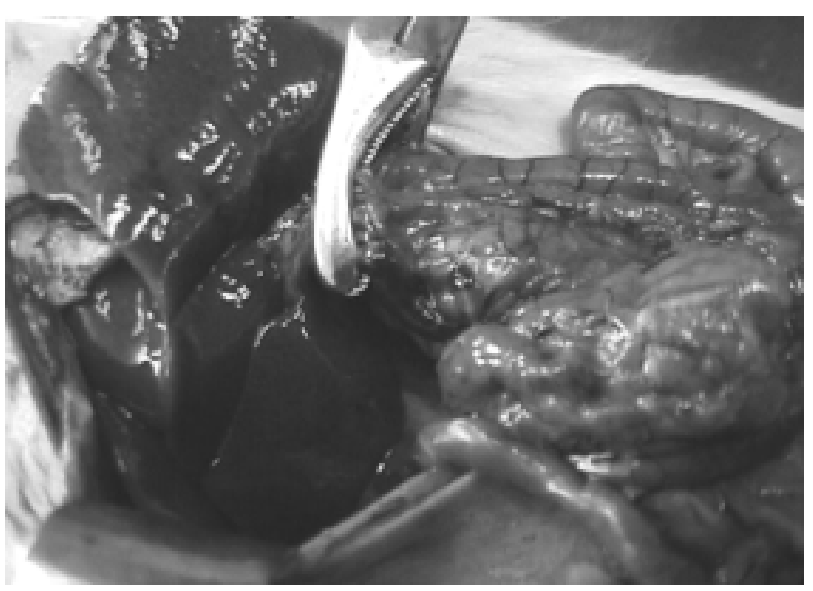

Figura 2 - Clampeamento do pedículo hepático.

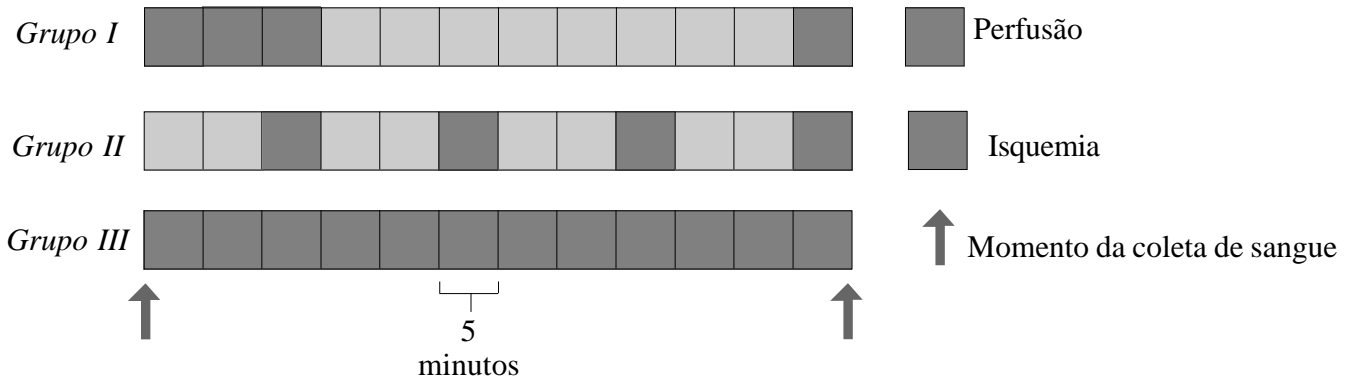

Figura 1 - Divisão dos grupos de acordo com o procedimento cirúrgico utilizado. 
- Grupo II (Clampeamento intermitente da tríade portal): imediatamente após a laparotomia, o pedículo hepático era identificado e clampeado. Realizamos quatro ciclos de 10 minutos de isquemia com intervalos de 5 minutos de reperfusão. Após 5 minutos do último desclampeamento nova amostra de sangue era colhida. Procedia-se à síntese da aponeurose e pele da mesma forma.

- Grupo Controle (Sem clampeamento da tríade portal): após a laparotomia não era realizado clampeamento algum. Aguardávamos 60 minutos, colhíamos a amostra de sangue e procedíamos à síntese da aponeurose e pele da mesma forma.

O tempo total de isquemia hepática normotérmica nos Grupos I e II foi o mesmo: 40 minutos. Nestes, o período de reperfusão anterior à última coleta de sangue também foi o mesmo: 5 minutos. O tempo operatório total até a segunda coleta das amostras nos três grupos foi de 60 minutos.

Para cada enzima foram calculados os valores médios, a variação absoluta (T1-T2) e a variação percentual dos dados obtidos nos três grupos de acordo com os momentos da coleta: no início (T1) ou no final da cirurgia (T2). Procedeu-se, então, à análise comparativa entre os grupos.

Os testes estatísticos utilizados foram: a) Análise de variância: compara os três grupos e especifica em que ponto eles diferem; b) Teste de comparações múltiplas de Tukey: também tem a função de comparar os três grupos, indicando em que ponto diferem; c) Teste T de Student emparelhado: de forma diferente do Teste T de Student, que avalia dois grupos num mesmo tempo, o teste emparelhado permite o estudo das variações ocorridas num mesmo animal ou grupo com o passar do tempo.

Observação: devido a grande variabilidade dos dados foi utilizada a transformação logarítmica para fins de análise.

Foi definido como valor significativo: $\mathrm{p}<0,05$.

\section{RESULTADOS}

Os valores médios, a variação absoluta (T1-T2) e a variação percentual dos dados obtidos nos três grupos podem ser encontrados na Tabela 1 e nas Figuras 3, 4 e 5.

Os três grupos do trabalho foram considerados comparáveis por apresentar o mesmo sexo, peso semelhante, além de terem sido submetidos às mesmas condições préoperatórias e anestésicas, e terem tido o mesmo tempo operatório.

\section{Transaminase Glutâmico Oxalacética (TGO)}

Não houve diferença significativa $(p=0,63)$ nos níveis basais (T1) de TGO entre os três grupos, sendo, portanto, passíveis de comparação.

Todos os grupos, inclusive o grupo controle, apresentaram um aumento significativo do momento 1 (T1) para o momento 2 (T2) (Controle: $\mathrm{p}=0,04$; Grupo I: $\mathrm{p}=$ 0,0001; Grupo II: $p=0,0001)$.

Há diferença significativa $(p=0,0001)$ no aumento médio entre os três grupos. $\mathrm{O}$ aumento do grupo controle é significativamente menor do que o dos grupos I e II, sendo o aumento do grupo I significativamente maior do que o do grupo II. Assim, temos: Controle < Grupo II < Grupo I.

\section{Transaminase Glutâmico Pirúvica (TGP)}

Não houve diferença significativa $(p=0,89)$ nos níveis basais (T1) de TGP entre os três grupos, o que permite estudo comparativo.

Todos os grupos apresentaram um aumento significativo do momento 1 para o momento 2 (Controle: $\mathrm{p}=$ 0,03; Grupo I: $p=0,0001$; Grupo II: $p=0,0001$ ).

Há diferença significativa $(p=0,0001)$ no aumento médio entre os três grupos. O aumento do grupo controle é significativamente menor do que o dos grupos I e II, sendo o aumento do grupo I significativamente maior do que o do grupo II. Assim, temos: Controle < Grupo II < Grupo I.

Tabela 1

Média dos valores obtidos na dosagem de TGO, TGP e LDH (UI/L)

\begin{tabular}{l|c|c|c|r|r|r}
\hline Enzima & Grupo & Amostra & $T 1$ & $T 2$ & Variação Absoluta & Variação \% \\
\hline TGO & Controle & 10 & 320,70 & 385,20 & 64,50 & 19,18 \\
& Grupo I & 10 & 302,00 & 1737,00 & 1435,00 & 515,76 \\
& Grupo II & 10 & 273,60 & 797,10 & 523,50 & 209,59 \\
TGP & & & & & 58,20 & 60,28 \\
& Controle & 10 & 153,80 & 212,00 & 2426,80 & 1898,28 \\
& Grupo I & 10 & 159,90 & 2586,70 & 935,70 & 844,01 \\
LDH & Grupo II & 10 & 150,60 & 1086,30 & 446,50 & 21,43 \\
& Controle & 10 & 2044,40 & 2490,90 & 4182,30 & 184,62 \\
& Grupo I & 10 & 2801,90 & 6984,20 & 1009,60 & 43,15
\end{tabular}

TGO - Transaminase Glutâmico Oxalacética

TGP - Transaminase Glutâmico Pirúvica

LDH - Lactato Desidrogenase

Amostra: número de animais por grupo

T1 - Coleta de sangue no início da cirurgia

T2 - Coleta de sangue no final da cirurgia 


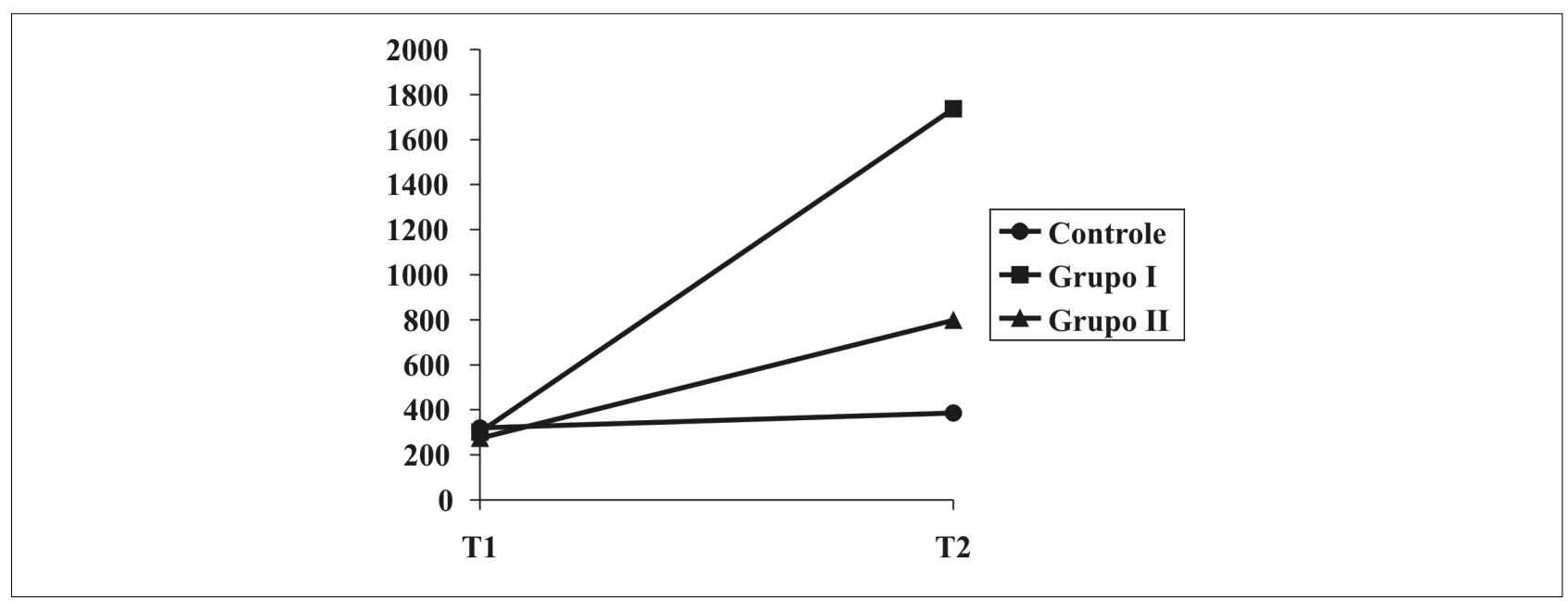

Figura 3 - Gráfico do resultado dos valores médios de Transaminase Glutâmico Oxalacética, TGO (UI/L) obtido no início (T1) e no final da cirurgia (T2).

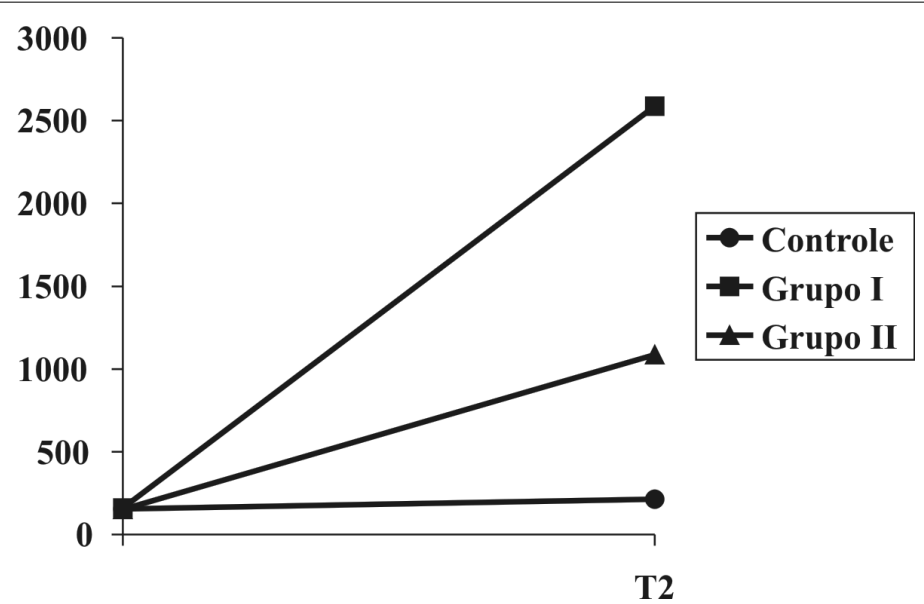

Figura 4 - Gráfico do resultado dos valores médios de Transaminase Glutâmico Pirúvica, TGP (UI/L) obtido no início (T1) e no final da cirurgia (T2).

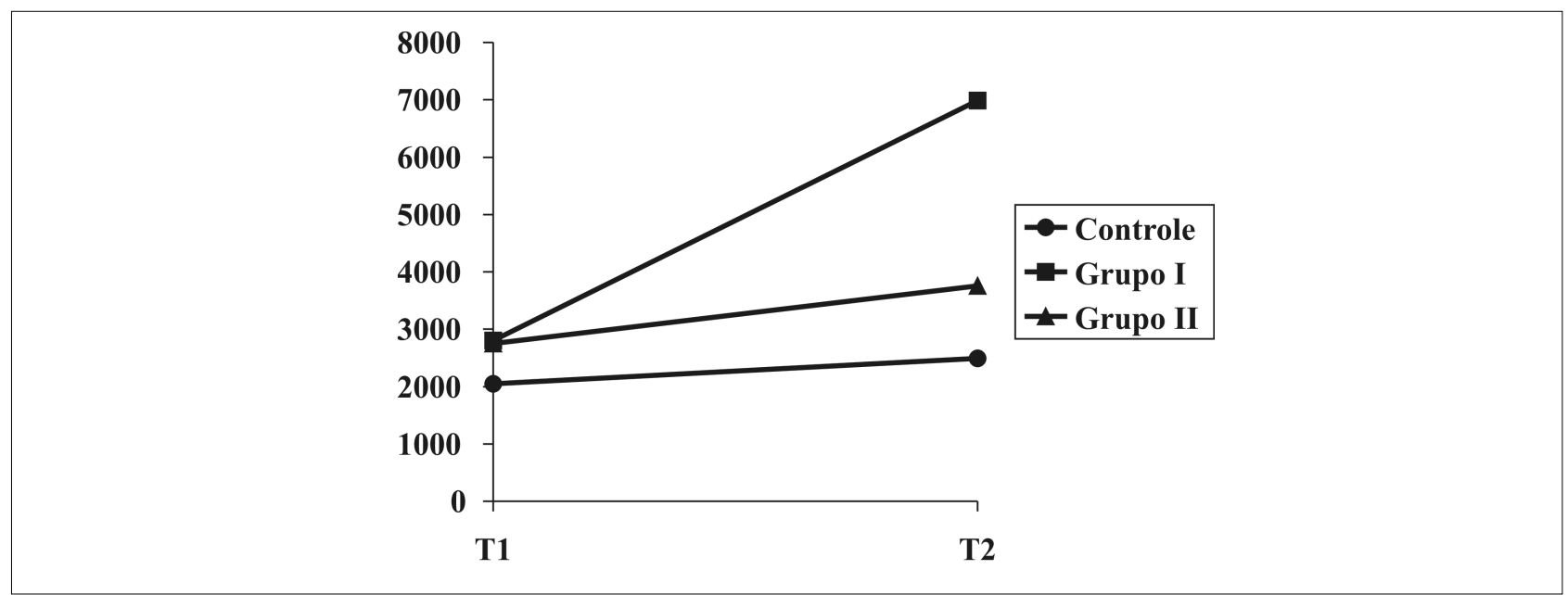

Figura 5 - Gráfico do resultado dos valores médios de Lactato Desidrogenase, LDH (UI/L) obtido no início (T1) e no final da cirurgia (T2). 


\section{Lactato Desidrogenase (LDH)}

Não há diferença significativa $(\mathrm{p}=0,12)$ nos níveis basais (T1) de LDH entre os três grupos.

Todos os grupos apresentam aumento significativo do momento 1 para o momento 2 (Controle: $\mathrm{p}=0,01$; Grupo I: $p=0,0001$; Grupo II: $p=0,001$ ).

Não houve diferença estatística nas variações entre o grupo II e grupo controle, porém, o aumento do grupo I é significativamente maior do que o dos grupos Controle e II. Assim temos: Controle = Grupo II < Grupo I.

\section{DISCUSSÃO}

A importância da cirurgia hepática pode ser avaliada pelo grande número de publicações encontrado na literatura. O fígado se apresenta em posição de destaque nas cirurgias de emergência por ser o órgão mais lesado no trauma abdominal geral, já que ocupa a segunda colocação tanto no traumatismo fechado, onde o baço é o primeiro, como no trauma aberto, onde o intestino delgado o precede ${ }^{4,5}$

A maioria das lesões encontradas no momento da laparotomia é de baixa complexidade, constituindo pequenas lacerações ou hematomas subcapsulares. Muitas delas já não apresentam sangramento ativo. Lesões mais complexas, no entanto, em decorrência do vulto do sangramento, tornam imperioso o controle do fluxo sangüíneo hepático aferente e algumas vezes do eferente. A manobra mais utilizada para este fim é a manobra de Pringle ${ }^{6}$, descrita em 1908, que consiste no clampeamento de todo o pedículo hepático. Esta manobra permite a melhor visualização das lesões, facilitando o controle definitivo do sangramento. Além de sua utilidade no trauma, a possibilidade do controle per-operatório do sangramento através desta manobra encorajou sua utilização também nas cirurgias eletivas para ressecções de lesões ou segmentos doentes, onde se destacam mundialmente as ressecções de metástases hepáticas dos carcinomas colorretais. O clampeamento da tríade portal apresenta, no entanto, os inconvenientes da hipóxia tecidual, refletidos em graus variados de alterações histológicas e funcionais induzidos pela isquemia.

Com o objetivo de minimizar as lesões provocadas pela isquemia e pela reperfusão alguns estudos foram elaborados utilizando a manobra de Pringle por curtos períodos, seguidos de reperfusão em vários ciclos ${ }^{7-14}$. Teoricamente, nos pequenos intervalos em que o órgão era perfundido haveria retorno da atividade aeróbia, o que diminuiria a produção de ácido láctico e radicais livres, já sabidamente envolvidos na etiologia da lesão celular. Esta modalidade de clampeamento, o clampeamento intermitente, foi o objeto deste estudo ${ }^{2,3}$.

A possibilidade de minimizar a lesão do hepatócito durante a cirurgia hepática seja ela eletiva ou emergencial nos motivou a criar um modelo experimental em ratos em que comparamos o grau de lesão celular, medido por dosagem enzimática, decorrente de clampeamentos contínuos e intermitentes para um mesmo tempo total de isquemia (40 minutos). A escolha do ciclo de 10 minutos de isquemia com 5 minutos de reperfusão, descrita no método do nosso trabalho, não foi aleatória. Este é o ciclo mais freqüentemente utilizado na prática clínica, em humanos. Alguns autores preferiram utilizar ciclos com períodos de isquemia e/ou reperfusão maiores (12 ou 15 minutos de isquemia, 10 ou 15 minutos de reperfusão) em seus trabalhos experimentais $7,12,13,15$.

Como parâmetro de avaliação de lesão celular utilizamos a dosagem plasmática da Transaminase Glutâmico Oxalacética (TGO), da Transaminase Glutâmico Pirúvica (TGP) e da Lactato Desidrogenase (LDH). Estas enzimas são intracelulares, sendo liberadas no interstício e na circulação no momento em que a célula, no caso o hepatócito, se rompe. A principal causa de sua ruptura é a isquemia. A falta de energia secundária à hipóxia prejudica $\mathrm{o}$ funcionamento da bomba de sódio-potássio-ATPase, permitindo o influxo celular de grande quantidade de sódio e água levando à ruptura celular. A utilização das transaminases e da LDH como parâmetro de lesão do hepatócito vem sendo bem demonstrada em diversos estudos, como o de Isozaki ${ }^{8}$, Kimura $^{9}$, Luo $^{16}$, Nishimura ${ }^{17}$, Urakami ${ }^{15}$ e van Wagensveld ${ }^{12,13}$.

A coleta do sangue do animal foi realizada através de punção direta com agulha fina da veia cava supra-hepática. A veia cava supra-hepática do rato é longa $(1 \mathrm{~cm})$ e calibrosa ( $3 \mathrm{a} 4 \mathrm{~mm}$ ), o que facilita a coleta. Outra vantagem encontrada é que ela recebe grande fluxo de sangue proveniente diretamente do fígado, órgão em estudo. $\mathrm{O}$ volume de $1 \mathrm{ml}(0,5 \mathrm{ml}$ por punção) representa aproximadamente $1 / 15$ da volemia do rato, que por si só não afetaria de maneira importante as condições hemodinâmicas do animal. Por outro lado, quando associamos a anestesia geral inalatória e o clampeamento pedicular hepático provocamos, provavelmente, um certo grau de hipotensão. A anestesia geral e a coleta de sangue estavam presentes no três grupos.

A TGO e a LDH não são enzimas exclusivas do fígado. Podem ser encontradas também, por exemplo, nas musculaturas esquelética e cardíaca. A melhor perfusão tecidual destes órgãos no grupo controle, já que não houve clampeamento e, conseqüentemente, um menor grau de hipotensão poderia ser um viés que beneficiaria este grupo na dosagem destas enzimas. A restauração temporária do fluxo hepático, observada no grupo II, também melhoraria a hipotensão e, portanto, a perfusão destes órgãos. Com a inclusão da dosagem da TGP, enzima encontrada apenas no hepatócito, a possibilidade de que a elevação de TGO e LDH derivasse da má perfusão de outros órgãos e não somente do fígado, diminui sensivelmente. Nossos resultados, inclusive, demonstraram que dentre as enzimas estudadas, a TGP foi a que apresentou elevações mais significativas atingindo 1898,28\% no grupo I em relação à média de seus níveis basais. A TGO atingiu 515,76\% e a LDH, $184,62 \%$ no mesmo grupo.

Além das enzimas descritas, outros dados podem ser utilizados para a monitorização da lesão do hepatócito como: metabolismo de $\mathrm{N}$ colesterol ${ }^{18}$, ATP hepático ${ }^{19}$, regeneração de radicais livres ${ }^{11}$, tensões de $\mathrm{CO}_{2} \mathrm{e}_{2}$ no tecido hepático e ácido hialurônico ${ }^{12,13,15}$, ativação de calpain 
$\mathrm{mu}^{14}$, a elevação de xantinas e ATP ${ }^{20}$, fator de necrose tumoral e interleucina 6 (IL 6) ${ }^{9}$, avaliação do fluxo hepático, a análise histológica e a dosagem de bATP ${ }^{7}$. Apesar de existirem muitas opções entre as diversas substâncias utilizadas para qualificar e quantificar a lesão da célula hepática optamos pela dosagem de TGO, TGP e LDH por quatro motivos principais: 1) muitos dos estudos que utilizam outras substâncias também fazem dosagem de uma ou mais destas enzimas $9,12,13,15,17$; 2) são as substâncias mais freqüentemente encontradas na literatura na avaliação do dano celular; 3) são de fácil acesso, podendo ser dosadas em qualquer laboratório; 4) são, efetivamente, o que utilizamos na prática clínica no acompanhamento de nossos doentes.

Para que não houvesse interferência do tempo operatório e anestésico nos resultados, assim como Wang ${ }^{14}$, tivemos o cuidado de manter o mesmo tempo operatório (60 minutos) nos três grupos, incluindo o grupo controle.

Os resultados aqui apresentados demonstraram elevação das três enzimas estudadas do momento 1 (T1) para o momento 2 (T2) em todos os grupos. Nos grupos I e II as variações foram, no entanto, bem mais significativas do que a elevação ocorrida no grupo controle. O aumento estatisticamente significativo ocorrido neste grupo não era esperado. Acreditamos que possa ser decorrente da ação direta do anestésico (éter) na célula hepática, combinado à hipotensão secundária à diminuição da volemia (coleta de sangue) e anestesia geral, acarretando menor oferta de $\mathrm{O}_{2}$ ao tecido hepático. Houve significativa diferença estatística entre os grupos na análise das três enzimas. Só não houve diferença significativa entre o grupo controle e o grupo II na avaliação da LDH. A elevação das três enzimas no grupo I, do momento 1 (T1) para o momento 2 (T2) foi significativamente maior que no grupo II $(p=0,0001)$. A análise destes dados nos permitiu verificar que o clampeamento intermitente, exceto na avaliação da $\mathrm{LDH}$, provoca significativamente mais lesão celular do que o grupo controle. O clampeamento contínuo, no entanto, provoca lesões ainda maiores, com diferença significativa na dosagem das três enzimas com relação ao clampeamento intermitente.
Foram poucos os trabalhos encontrados na literatura que compararam o grau de lesão celular do hepatócito nas duas modalidades de clampeamento apresentadas. Além disso, alguns utilizaram parâmetros de lesão celular diferente dos nossos, assim como incluíram a avaliação de animais cirróticos e ictéricos ${ }^{1}$. A utilização de outros parâmetros, contudo, não inviabiliza a comparação, pois o resultado da proteção ou não do hepatócito pela utilização do clampeamento intermitente é o que realmente importa. Nosso trabalho utilizou apenas animais sem doença hepática, o que foi confirmado pela igualdade estatística dos valores basais das três enzimas estudadas entre os 30 ratos incluídos no estudo.

Na literatura não encontramos nenhum trabalho com a metodologia exatamente igual à utilizada por nós. Entretanto, vários trabalhos que compararam os dois tipos de clampeamento, mesmo que com a utilização de intervalos de isquemia e reperfusão diferentes ou de animais doentes ou sadios na metodologia, utilizando-se uma avaliação enzimática precoce ou tardia ${ }^{8,9,11,13,20}$, chegaram às mesmas conclusões: há benefício da utilização do clampeamento intermitente, especialmente em situações de necessidade de isquemia prolongada.

O conhecimento da maior proteção do hepatócito no clampeamento intermitente abre caminho para novos estudos, experimentais ou clínicos, dos mecanismos envolvidos na lesão celular induzida pela isquemia normotérmica. As implicações na regeneração tecidual, o benefício no desenvolvimento de cirrose ou de insuficiência hepática, o ciclo ideal de clampeamento intermitente e os resultados na presença de patologias associadas são exemplos de temas a serem estudados com grande poder aplicativo no nosso cotidiano.

Os dados encontrados em nossa experimentação nos permitiu concluir que o clampeamento intermitente do pedículo hepático, em ciclos de 10 minutos de isquemia e cinco minutos de reperfusão, provoca menor lesão do hepatócito, para um mesmo tempo total de isquemia de 40 minutos, em fígado de ratos normais, se comparado ao clampeamento contínuo.

\begin{abstract}
Background: Our objective was to access the biochemical alterations due to hepatic warm ischemia followed by reperfusion in two modalities of portal triad clamping in rats. Method: We divided thirty male Wistar rats, weighting between 250 and 320 grams into three groups with 10 animals each. Forty minutes of hepatic ischemia was induced by continuous (group I) or intermittent (group II) clamping. No clamping was used in control group. As a parameter of hepatocelular injury, plasma concentrations of glutamic oxaloacetic transaminase $(G O T)$, glutamic pyruvic transaminase (GPT) and lactate dehydrogenase ( $L D H)$ were measured. Blood specimens were obtained at the begining (T1) and at the end of the surgery (T2). All animals had the same operative time, 60 minutes. Results: There was not statistic difference between baseline (T1) values of the three enzymes in all groups. All animals showed significant increases of all enzymes from moment 1 (T1) to moment 2 (T2). There was statistical difference in the mean increase of GOT and GPT between the three groups, but the greatest elevation was found in group I and the lowest, in control group. In LDH analysis, there was not significant difference between group II and control group. Group I, however, showed significant increases compared with the other two. Conclusion: Compared with the continuous clamping, to a total ischemic period of 40 minutes, intermittent portal triad clamping, in rats, with 10/5 minutes ischemia/reperfusion cycles, leads to a lesser hepatocelular damage, verified by the lowest enzymatic values.
\end{abstract}

Key Words: Liver-blood flow; Ischemia; Reperfusion; Constriction; Rats. 


\section{REFERÊNCIAS}

1. Blumgart LH, Wheatley AM, Mathie RT. Liver blood flow: physiology, measurement and clinical relevance. In Blumgart LH (ed) - Surgery of the Liver and Biliary Tract. $2^{\text {nd }}$ edition, New York. Churchill Livingstone, 1994, pp. 95-110.

2. Elias D, Desruennes E, Lasser P. Prolonged intermittent clamping of the portal triad during hepatectomy. Br J Surg, 1991, 78:42-4.

3. Elias D, Lasser P, Debaene B et al. Intermittent vascular exclusion of the liver (without vena cava clamping) during major hepatectomy. Br J Surg, 1995, 82: 1535-9.

4. Fabian TC, Croce MA. Abdominal Trauma, Including Indications for Celiotomy. In: Feliciano DV, Moore EE, Mattox KL (eds) - Trauma. $3^{\text {rd }}$ edition, Connecticut. Appleton \& Lange, 1996, pp. 441-59.

5. Pachter HL, Liang HG, Hofstetter SR. Liver and Biliary Tract Trauma. In: Feliciano DV, Moore EE, Mattox KL (eds) - Trauma. $3^{\text {rd }}$ edition, Connecticut. Appleton \& Lange, 1996, pp. 487-523.

6. Pringle JH. Notes on the arrest of hepatic hemorrhage due trauma. Ann Surg, 1908, 48:541-9.

7. Horiuchi T, Muraoka R, Tabo T et al. Optimal cycles of hepatic ischemia and reperfusion for intermittent pedicle clamping during liver surgery. Arch Surg, 1995, 130(7): 754-8

8. Isozaki $\mathrm{H}$, Okagima $\mathrm{K}$, Kobayashi $\mathrm{M}$ et al. Experimental study of liver injury after partial hepatectomy with intermittent or continuous hepatic vascular occlusion. Differences in tolerance to ischemia between normal and cirrhotic livers. Eur Surg Res, 1995, 27(5): 31322.

9. Kimura N, Muraoka R, Horiuchi T et al. Intermittent hepatic pedicle clamping reduces liver and lung injury. $\mathrm{J}$ Surg Res, 1998, 78(1): 11-7.

10. Nitta N, Yamamoto S, Ozaky $\mathrm{N}$ et al. Is the deterioration of liver viability due to hepatic warm ischemia or reinflow of pooled-portal blod in intermittent portal triad cross-clamping? Res Exp Med (Berl.), 1988, 188(5): 341-50.

11. Uchinami M, Muraoka R, Horiuchi T et al. Effect of intermittent hepatic pedicle clamping on free radical generation in the rat liver. Surgery, 1998, 124(1): 49-56.

12. van Wangesveld BA, van Gulik TM, Gabeler EE et al. Intrahepatic tissue $\mathrm{pO}_{2}$ during continuous or intermittent vascular inflow occlusion in a pig liver resection model. Eur Surg Res, 1998, 30(1): 13-25.

13. van Wangesveld BA, van Gulik TM, Gelderblom HC et al. Prolonged continuous or intermittent vascular inflow occlusion during hemihepatectomy in pigs. Ann Surg, 1999, 229(3): 376-84.

14. Wang M, Sakan M, Umoshita K et al. Determination of a safe vascular clamping method for liver surgery: evaluation by measuring activation of calpain mu. Arch Surg, 1998, 133(9): 983-7.

15. Urakami A, Hirai R, Ota $\mathrm{T}$ et al. Continuous measurement of tissue oxigen and carbon dioxide gas tensions in dog liver ischemia/reperfusion. Acta. Med. Okayama, 1996, 50(6): 285-92.

16. Luo MD, Daí ZB. Experimental study on hepatic inflow occlusion in rabbits. Chin Med J (Engl.), 1994, 107(11): 850-3.
17. Nishimura T, Nakahara M, Kabayashi $\mathrm{S}$ et al. Ischemic injury in cirrhotic livers: an experimental study of the temporary arrest of hepatic circulation. J Surg Res, 1992, 53(3): 227-33.

18. Hayakawa Y, Yoshioka Y, Yasuda N. Effects of ligation and reperfusion of hepatic afferent vessels on the composition of liver cell membrane in the rat: $1 \mathrm{H}$ and $31 \mathrm{P}$ magnetic resonance spectroscopic analysis. NMP Biomed, 1997, 10(6): 257-62.

19. Izu M. Investigation of hepatic energy metabolism in normothermic hepatic ischemia-comparison between normal and cirrhotic rat liver. Nippon Geka Gakkai Zasshi, 1992, 93(1): 52-61.

20. Watanabe K, Hayashi M, Senga S et al. Changes in high energy phosphates and tissue blood flow in ischemia and reperfusion of jaundiced rat liver - effect of intermittent brief ischemia. Nippon Geka Gakkai Zasshi, 1993, 94(8): 796-800.
Endereço para correspondência:

Fábio Neves da Silva

Rua Jerônimo Monteiro, 10/1001 — Leblon 